\title{
The comparison of cognitive function disorder before and after early therapy for cerebral toxoplasmosis in HIV/AIDS patients
}

\author{
Badrul Munir'1 , Sri Budhi Rianawati², Harun Al Rosyid ${ }^{3}$ \\ ${ }^{1}$ Division of Neuroinfection, Department of Neurology, Faculty of Medicine, Brawijaya University, Malang, East Java, Indonesia \\ ${ }^{2}$ Division of Neurobehavior, Department of Neurology, Faculty of Medicine, Brawijaya University, Malang, East Java, Indonesia \\ ${ }^{3}$ Public Health, Faculty of Medicine, Brawijaya University, Malang, East Java, Indonesia
}

\begin{abstract}
Introduction: Toxoplasmosis is a common opportunistic disease that also affects human immunodeficiency virus (HIV)/acquired immunodeficiency syndrome (AIDS) patients, but there are currently no research studies about cognitive function in cerebral toxoplasmosis patients, especially in terms of the effect of early treatment for this disease. The aim of the study was to compare cognitive function disorder of cerebral toxoplasmosis patients before and after early treatment of cerebral toxoplasmosis.

Material and methods: The longitudinal study were conducted among neuroinfection patients who registered in the Neurology Department of Saiful Anwar Hospital, Malang, Indonesia during JanuaryDecember 2016. The inclusion criteria were: cerebral toxoplasmosis patients, HIV-positive status, head computed tomography (CT) scan performed, IgG and IgM toxoplasmosis, and patients willing participate in the study. The exclusion criteria were: other masses in the brain besides toxoplasmaderived, depression, patients not cooperative, or loss of consciousness. Samples were taken by continuous random sampling with Mini-Mental State Examination and Clock Drawing Test. The duration for anti-toxoplasma early therapy was 2-4 weeks.

Results: From a total of 31 patients, 13 patients met the inclusion criteria, with an average age of 37 years old (range, 26-67 years). The average CD4+ was $45.75 \mathrm{dl}$ (8-85 dl). The result of cognitive function examination for pre-therapy was 24.85 and after therapy $26.54(p=0.07)$. The clock-drawing test before treatment was 3.15 and increased to 3.39 after treatment $(p=0.41)$.

Conclusion: No significant difference in cognitive function disorder before and after cerebral toxoplasmosis early therapy was found.
\end{abstract}

HIV AIDS Rev 2020; 19, 1: 30-33

DOI: https://doi.org/10.5114/hivar.2020.93159

Key words: clock-drawing test, cognitive function, HIV/AIDS, mini-mental state examination, toxoplasmosis.

\section{Introduction}

Human immunodeficiency virus (HIV)/acquired immunodeficiency syndrome (AIDS) has become a global problem.

More than 95\% of AIDS cases are found in developing countries. The average seroprevalence in adults starts from less than $1 \%$ in India and Europe to more than $10-20 \%$ in some African countries [1]. In HIV/AIDS patients, Toxoplasma gondii

\section{Article history:}

Received: 14.04.2019

Received in revised form: 08.08.2019

Accepted: 13.08.2019

Available online: 13.02 .2020
International Journal of HIV-Related Problems

HIV \& AIDS

R e vi e w 
infection can cause cerebral toxoplasmosis; the decreased immune system allows T. gondii to proliferate, reactivating from latent infection, and becoming a severe disease [1].

Latent infection of T. gondii is suspected as the cause of a decrease of cognitive function in HIV/AIDS patients, measured using the speed of thinking processes and shortterm memory as parameters [2].

In HIV/AIDS patients, T. gondii infections can cause cerebrum toxoplasmosis. In the immune deficit condition, T. gondii reactivates from latent infection and become a disease. T. gondii can become reactivated when T-CD4+ cells are below a concentration of $100 \mathrm{cell} / \mu \mathrm{l}$, or if T-CD4+ levels drop below $100 \mathrm{cell} / \mu \mathrm{l}$ due to an opportunistic infection or malignancy that accompanies the disease. If not handled properly, it can be life-threatening condition. Cerebrum toxoplasmosis is a common cause of cerebral abscesses in people with AIDS [3, 4].

In advanced countries that implement high active antiretroviral therapy (HAART) widely, AIDS patients can survive longer. By using HAART, HIV/AIDS can shift into a chronic disease that can be controlled [5].

HAART medicines can decrease the incidence of cognitive disorder related to HIV (from mild cognitive disorder to HIV-associated dementia/HIV-D condition), such as op-

Table 1. Toxoplasmosis patients' basic data gathered for 1 year

\begin{tabular}{|c|c|}
\hline Parameter & Result \\
\hline Age (year) & $34(26-39)$ \\
\hline Gender, male : female, $n(\%)$ & $12: 19(40: 60)$ \\
\hline \multicolumn{2}{|l|}{ HIV transmission, $n(\%)$} \\
\hline Free sexual, homosexual & $15(50)$ \\
\hline Drugs, tattoo & $7(24)$ \\
\hline Unknown & $9(26)$ \\
\hline \multicolumn{2}{|l|}{ Occupation, $n$ (\%) } \\
\hline Private business & $7(24)$ \\
\hline Housewife & $6(18)$ \\
\hline Jobless & $20(62)$ \\
\hline \multicolumn{2}{|l|}{ Duration of HIV diagnosis given, $n(\%)$} \\
\hline$<1$ month & $21(69)$ \\
\hline 1-12 months & $10(33)$ \\
\hline$>12$ months & $7(21)$ \\
\hline \multicolumn{2}{|l|}{ Level CD4+ ( $t$ test $)$} \\
\hline Before toxoplasmosis early therapy & 39.86 \\
\hline After toxoplasmosis therapy & 51.71 \\
\hline \multicolumn{2}{|l|}{ Sexual orientation, $n(\%)$} \\
\hline Heterosexual & $25(82)$ \\
\hline Homosexual & $6(18)$ \\
\hline \multicolumn{2}{|l|}{ Outcome, $n(\%)$} \\
\hline Alive & $17(56)$ \\
\hline Deceased & $14(44)$ \\
\hline
\end{tabular}

portunistic infection of the central nerve system (CNS) and distal sensory polyneuropathy associated with HIV [6-9].

Toxoplasma therapy with several anti-toxoplasmic phases, from the acute phase to the maintenance phase, provides good results, decreasing patient mortality, and disability rate; however, no research has been published on evaluation of the effect of such therapy on cognitive function, particularly post-acute toxoplasma therapy.

\section{Material and methods}

This present research was conducted after obtaining ethical approval from the Saiful Anwar Hospital, Malang, Indonesia, No.400/12/K.3/302/20015.

This was a longitudinal study, and samples were chosen using continuous random sampling from patients registered in the Saiful Anwar Hospital, Malang, East Java Indonesia from January to December 2016. In total, 31 patients were participating in this study, comprised of 12 females and 19 males (Table 1).

Inclusion criteria were cerebrum toxoplasmosis HIVpositive patients, immunoassay examination, contrast head CT scan performed, an increase in IgG/IgM titers, high consciousness (GCS 456) patients, and the will to participate in the study by signing an informed consent.

Exclusion criteria involved meningoencephalitis, cerebral tuberculoma, or another brain mass other than toxoplasma (cerebral tumor or cerebral abscess).

The independent variable in this study was initial toxoplasmosis therapy. The variable depends on patient cognitive function level that can be measured with neuropsychologist tests such as the Mini-Mental State Examination (MMSE) and Clock Drawing Test (CDT). MMSE is a simple standard assessments for screening of cognitive impairment, which is often carried out by both health care and research practices especially in dementia [10], while CDT is a simple neuropsychometric assessment to asses several cognitive functions [11].

The statistical analysis process used a comparative examination of Wilcoxon test, $t$-tail with SPSS 23 program to test treatment differences.

\section{Results}

After one year of gathering the data, 31 cerebrum toxoplasmosis patients were treated in Saiful Anwar Malang Hospital. An average age of patients was 34 years, and there were more female patients (19) compared to male patients (12). Mostly, HIV had been transmitted to these patients by unsafe sexual intercourse; the HIV diagnosis was generally at the patient's first hospitalization, with very low CD4+ level (39.86\%).

MMSE test results before the therapy was $24.846( \pm 3.891)$, which means that patients experienced almost mild cognitive disorder. And after the treatment, an average MMSE increased to 26.539 ( \pm 3.256 ). However, this improvement was not statistically significant (Table 2). 
The CDT parameters showed that the average or median CDT results before the therapy was lower compared to that after the treatment. However, based on the Wilcoxon test results, there was no significant difference in CDT findings before and after the therapy.

\section{Discussion}

\section{Explanation}

The epidemiology data showed that cerebrum toxoplasmosis patients are mostly young. This is in agreement with previous data from the same hospital from 2014-2015 that showed that the average age of toxoplasmosis patients was 33.5 years old (range, 27-35 years), with more male patients compared to female patients. The high percentage of young patients is caused by young trending distribution of HIV/AIDS [12].

The average CD4+ level in cerebrum toxoplasmosis patients was 39.8 corresponding with the previous data, where the average level of CD4+ was 31 . The low CD4+ level indicates patients' weak immune level, and the lower the level, they more likely to contract cerebrum toxoplasmosis [12]. However, from the other study, there was a relationship between CD4+ level and HIV dementia.

Mortality rate was also very high at $44 \%$. It was lower compared to another study conducted in the same hospital, with a rate of $66.4 \%$. The high-rate is caused by the severity of HIV disease and other complications from correlated disorders [12].

\section{The difference of cognitive function before and after the therapy}

There was no significant difference for statistical test and unpaired $t$-test on MMSE average value before and after early therapy of cerebrum toxoplasmosis $(p>0.05)$ [12].

From 13 subjects that were examined, very few of them experienced a decreasing value in MMSE test. Subjects with almost the same MMSE value before and after the test consisted of about $46.15 \%$. The reason for this results may be the nature of toxoplasmosis, which is a focal disorder with a mass of parasitic infections, and the effect of clinical manifestation is based on the injection location. Cognitive disorders generally tend to disseminate in the brain, and are caused by an inflammatory reactions, which triggers damage to neurons, particularly influencing the memory.

Based on the Wilcoxon test evaluations, there was no significant difference in CDT results before and after early therapy of cerebrum toxoplasmosis. This examination should be performed if there is a cognitive disorder, especially vision spatial disorders in some cases. In this study, the CDT levels were almost normal before starting the therapy and slightly improved after early toxoplasmosis treatment. In future, the examination of spatial vision disorders is needed if the disease is related to lesion location, as seen in radiology images of cerebrum toxoplasma patients.
Table 2. The result of before and after therapy

\begin{tabular}{l|c|c}
\hline Parameter & Before & After \\
\hline $\begin{array}{l}\text { Average } \\
\text { (standard intersection) }\end{array}$ & $24.846( \pm 3.891)$ & $26.539 \pm 3.256)$ \\
\hline $\begin{array}{l}\text { Median } \\
\text { (percentile 25-75) }\end{array}$ & $23(22.0-29.0)$ & $28(22.5-29.5)$ \\
\hline Paired $t$-test result & \multicolumn{2}{|c}{$p=0.070$ Wilcoxon test } \\
\hline
\end{tabular}

Table 3. The comparison of clock-drawing test results before and after therapy

\begin{tabular}{l|c|c}
\hline Parameter & Before & After \\
\hline Mean (SD) & $3.154( \pm 1.068)$ & $3.385( \pm 1.325)$ \\
\hline Median (percentile 25-75) & $3(3.0-4.0)$ & $4(2.0-4.0)$ \\
\hline Significant Wilcoxon test & \multicolumn{2}{|c}{$p=0.408$} \\
\hline
\end{tabular}

The limitation of this study was relatively short time of MMSE and CDT assessment for pre- and post-early therapy. The initial treatment of cerebrum toxoplasmosis is about six weeks and then continued with a maintenance dose. In this study, the cognitive examination was completed one day before patients were allowed to go home, with inpatient time ranging from 3 to 4 weeks in the hospital. This may cause the results of this study to be biased.

Further study is needed to understand the long-term effect of toxoplasmosis therapy. The therapy should be maintained for $6,9,12$, and 24 months to evaluate the difference in patients' cognitive function after the treatment.

Another weakness of this therapy was that the antiretroviral (ARV) factor was not included, because when MMSE and CDT level is being measured, the ARV treatment cannot be started to ensure the recovery from opportunistic disease and to avoid complications of ARV therapy, especially the occurrence of immune reconstitution inflammatory syndrome. Some studies have shown that ARV therapy on HIV patients could decrease the possibility of dementia, although sometimes ARV therapy can trigger dementia.

The complexity of this study was that cognitive tests need a quiet environment, take a long time to administer, and should be carried out in a sitting position. However in this study, there were some difficulties such as measurements being performed in the same inpatients' room, which is not ideal for examining both MMSE and CDT. Additionally, cognitive tests should be administered by well-trained staff, but in this study, tests were conducted by a neurology resident who happened to be in the room.

\section{Conclusions}

As seen from MMSE and CDT outcomes, there was no significant improvement on the cognitive function before and after early therapy of cerebrum toxoplasmosis in HIV/ AIDS patients. 


\section{Acknowledgement}

We would like to thank the director of the Saiful Anwar Hospital, dean of the Faculty of Medicine of Brawijaya University, all the research team, and the staff in the Neurology Department of the Medical Faculty of Brawijaya University and Saiful Anwar Hospital, Malang.

\section{Conflict of interest}

The authors declare no conflict of interest with respect to the research, authorship, and/or publication of this article.

\section{References}

1. Karim QA. Current status of the HIV epidemic \& challenges in prevention. Indian J Med Res 2017; 146: 673-676.

2. Gale SD, Brown BL, Erickson LD, Berrett A, Hedges DW. Association between latent toxoplasmosis and cognition in adults: a crosssectional study. Parasitology 2015; 142: 557-565.

3. Addebbous A, Adarmouch L, Tali A, et al. IgG anti-toxoplasma antibodies among asymptomatic HIV-infected patients in Marrakesh-Morocco. Acta Trop 2012; 123: 49-52.

4. Jayawardena S, Singh S, Burzyantseva O, Clarke H. Cerebral toxoplasmosis in adult patients with HIV infection. Clin Med J Resid Hosp Physician 2008; 44: 17-24.

5. Saylor D, Dickens AM, Sacktor N, et al. HIV-associated neurocognitive disorder - pathogenesis and prospects for treatment. Nat Rev Neuro 2016; 12: 234-248.

6. Ellis RJ. Evidence-based treatment for HIV-associated dementia and cognitive impairment: why so little? PLoS Clin Trials 2007; 2: e15.

7. Lawler K, Mosepele M, Ratchiffe S, et al. Neurocognitive impairment among HIV-positive individuals in Botswana: a pilot study. J Int AIDS Soc 2010; 13: 15

8. Ross KL. Principles of Neurologic Infectious Diseases. McGraw-Hill Professional, New York 2005.

9. Sacktor N, McDermott MP, Marder K, et al. HIV-associated cognitive impairment before and after the advent of combination therapy. J Neurovirol 2002; 8: 136-142.

10. Boban M, Malojčić B, Mimica N, et al. The reliability and validity of the mini-mental state examination in the elderly Croatian population. Dement Geriatr Cogn Disord 2012; 33: 385-392.

11. Aprahamian I, Martinelli JE, Neri AL, Yassuda MS. The Clock Drawing Test: a review of its accuracy in screening for dementia. Dement Neuropsychol 2009; 3: 74-80.

12. Munir B, Candradikusuma D. Manifestations of HIV/AIDS in case neurology: epidemology study at Saiful Anwar hospital year 20132014. Malang Neurology Journal 2015; 1: 7-11. 